\title{
Creation of a Kansas Spring Extreme Weather Syndrome Definition and Unique Records
}

\author{
Zachary M. Stein* \\ Bureau of Epidemiology and Public Health Informatics, Kansas Department of Health and Environment, Topeka, KS, USA
}

\section{Objective}

To evaluate syndrome definitions capturing storm- and extreme weather-related emergency department visits in Kansas hospitals participating in the National Syndromic Surveillance Program (NSSP).

\section{Introduction}

Kansas storms can occur without warning and have potential to cause a multitude of health issues. Extreme weather preparedness and event monitoring for public health effects is being developed as a function of syndromic surveillance at the Kansas Department of Health and Environment (KDHE). The Syndromic Surveillance Program at KDHE utilized emergency department (ED) data to detect direct health effects of the weather events in the first 9 months of 2016. Current results show injuries directly related to the storms and also some unexpected health effects that warrant further exploration.

\section{Methods}

A basic syndrome definition was defined based on extreme spring and summer weather events experienced in Kansas. This broad definition pulled records from Kansas EDs that included the following in the Chief Complaint or Triage Notes fields:

-Storm

-Rain

- Torna(dos)

$\bullet$ Wind

-Flood

This broad syndrome definition was performed on data submitted to the Kansas's production server through NSSP between January $1^{\text {st }}$ and August $30^{\text {th }}$, 2016. After the initial pull, duplicate records for the same patient and visit were removed.

The remaining set was then searched by hand to identify terms caught by the syndrome definition that were not related to storm activity or extreme weather. Record chief complaints were then scanned by hand to identify common words containing the search criteria and then removed. Keywords not of interest to the syndrome definition that were caught were: migraine, window, drain, restrain, train, and many other proper nouns that contained one of the keywords.

These remaining visits were then sorted by nature of visit and unexpected records were recorded for future direction of syndrome definition development.

\section{Results}

The initial data pull under these conditions yielded 17,691 unique emergency department visits from January $1^{\text {st }}$ to August $30^{\text {th }}$ during the 2016 year. From this, records were classified based on key words resulting in the pull. The table below shows the initial pull results, the remaining records after errant results were expunged, the percentage of visits that were removed, and the most common reason for removal.

Of these records remaining after cleaning, 20 were related to storms, 62 were related to rain, 7 were related to tornado activity, 66 were related to wind, and 14 were related to flooding along with the mixed variable instances shown in the table. A majority of the wind-related ED visits were injuries and the majority of the tornado activity events were related to injuries sustained while taking shelter.
Many of the injuries mentioning storms were sustained in preparation for the storm, and a handful were due to mental stresses regarding storm activity.

\section{Conclusions}

Syndrome definition development is an iterative process that will vary by region. By manually looking at line-level data details, future searches can better accommodate these errant results and false positives. These studies will facilitate more rapid extreme weather response in Kansas and allow better situational awareness. Along with general storm-related injuries, knowledge of the unusual records caught by a syndrome definition can also help direct public education in preparation of future storms. With injuries sustained while taking shelter and injuries sustained in preparation for the storm, we can take these unique ED visits and work on interventions to prevent future occurrences.

Case Counts Captured by Syndrome Definitions and Common False Positives

\begin{tabular}{|c|c|c|c|c|}
\hline Key Words & $\begin{array}{l}\text { Initial Syndrome } \\
\text { Definition Cases }\end{array}$ & $\begin{array}{l}\text { Remaining Cases after } \\
\text { Cleaning the Dataset }\end{array}$ & $\begin{array}{l}\% \text { of Cases } \\
\text { Removed }\end{array}$ & Most Common Reason for Removal \\
\hline Storm & 345 & 20 & $94.2 \%$ & Proper noun containing "storm" \\
\hline Rain & 16,292 & 62 & $99.6 \%$ & $\begin{array}{l}\text { Proper noun containing "rain" along with the } \\
\text { words migraine, drain, and restrain }\end{array}$ \\
\hline Torna & 7 & 7 & $0.0 \%$ & $\begin{array}{l}\text { Hospital note on admitted patient relocation } \\
\text { during tornado activity }\end{array}$ \\
\hline Wind & 836 & 66 & $92.1 \%$ & $\begin{array}{l}\text { Proper noun containing "wind" along with } \\
\text { non-storm-related window injuries }\end{array}$ \\
\hline Flood & 20 & 14 & $30.0 \%$ & Misspelled "floor" as "flood" \\
\hline $\begin{array}{c}\begin{array}{c}\text { Storm with } \\
\text { Rain }\end{array} \\
\end{array}$ & 23 & 1 & $95.7 \%$ & \\
\hline $\begin{array}{c}\text { Storm with } \\
\text { Wind }\end{array}$ & 8 & 1 & $87.5 \%$ & \\
\hline $\begin{array}{c}\text { Rain with } \\
\text { Wind }\end{array}$ & 156 & 4 & $97.4 \%$ & \\
\hline $\begin{array}{c}\text { Rain with } \\
\text { Torna }\end{array}$ & 1 & 1 & $0.0 \%$ & \\
\hline $\begin{array}{c}\text { Rain with } \\
\text { Flood }\end{array}$ & 2 & 0 & $100 \%$ & \\
\hline \begin{tabular}{|c|} 
Wind with \\
Flood
\end{tabular} & 1 & 0 & $100 \%$ & \\
\hline
\end{tabular}

\section{Keywords}

Syndromic Surveillance; Kansas; Storm; Weather; Injuries

\section{Acknowledgments}

Data collection was supported by the Grant or Cooperative Agreement Number 1 U50 OE000069-01, funded by the Centers for Disease Control and Prevention. Its contents are solely the responsibility of the authors and do not necessarily represent the official views of the Centers for Disease Control and Prevention or the Department of Health and Human Services.

\section{*Zachary M. Stein}

E-mail: zstein@kdheks.gov 